\title{
A High-Gain Three Port Converter Integrated with PV/Fuel Cell/Battery Sources Designed for HEV \& DC-Micro grid
}

\author{
${ }^{{ }^{* 1}}$ A. Srilatha, ${ }^{2}$ Dr. A. Pandian \\ ${ }^{1,2}$ Electrical \& Electronics Engineering Department, Koneru Lakshmaiah Education Foundation \\ Andhra Pradesh, India-522502
}

\section{Received: $15^{\text {th }}$ December 2017, Accepted: 20th January 2018, Published: $2^{\text {th }}$ February 2018}

\begin{abstract}
This paper suggests a new high-gain three-port converter using fuel cell, battery plus stacked output designed for HEV coupled todc-micro grid. In the anticipated converter, load power can distribute flexibly among input sources. The battery charging, discharging be controlled using FC. The anticipated converter output sare in series to attain a high output voltage, makes it suitable to interface with HEV and dc-micro grid. Going on with charging, discharging conditions of battery, two modes are welldefined.Theanticipatedpowerconvertercontainsoneb oostinductorcombinedusing fly back transformer; the boost and fly back circuit output terminals are stacked to rise output voltage gain and decrease voltage stress on the power devices. PV is combined to DC-DC converter to get high performance can be analyzed by using MATLAB/SIMULINK model.
\end{abstract}

Key Words: Hybrid electric vehicle, DCmicro grid, high-gain, two-port power converter, PV system.

\section{Introduction}

Nowadays renewable generation methods attain more attention owing to exhaustive nature of fuels and its bigger prices. Also the necessity for pollution free green energy has made a strong attention towards alternate energy sources. Solar energy stands the most available renewable source to encounter our fast growing energy desires [2].Peak power from PV unit is to be traced for its effective application. Several processes are obtainable in literature for tracing maximum power from solar panels. Modern improvements in renewable energy built power systems, HV's, aerospace systems, RES built smart grids and portable devices have brought challenges to design new DC-DC conversion systems[6][8]. This method composed of numerous input sources, combined through a multi-input power converter that can put up variety of input sources besides combine their benefits to provide measured output for varied applications [1]. EV's are the agents in charged transport, and this invention is currently evolving rapidly [4]. EVs have an excellent power profile that has both force usage and recovery at several moments of its process [3]. DC-DC converters are interfaced with power supply to load. On the basis of load desires, the parameters of source are adjusted. In conventional technique, each source of energy is coupled by its individual DC-DC converter whereas in multi-port DC-DC bustechnique, a single control for the multiple inputs, output ports[5] [7].

\section{Power Converter Operation Modes}

The suggested topology presented in Fig.1. In this figure, $R_{1} \sim R_{3}$ are model of load resistances that can symbolize the resultant power feeding dc micro grid. switches $S_{c}, S_{d}, S_{b}$, and $S_{o}$ in the converter structure are the main active switches which control power flow, voltage output of converter. The suggested converter, source $V_{\text {in } 1}$ can be capable to supply power to source $V_{\text {in2 }}$ but not vice versa. In this paper, FC is a generating power source $\left(\mathrm{V}_{\mathrm{in} 1}\right)$ and the battery a storage device $\left(\mathrm{V}_{\mathrm{in} 2}\right)$. Based on the state of battery, two power working modes are well-defined and examined for suggested converter as follows.

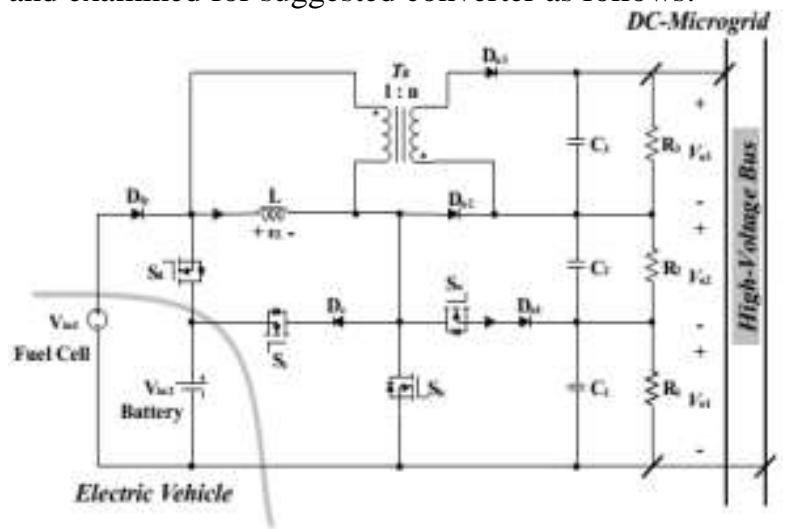

Fig.1. suggested converter with two-input, threeoutput ports for $\mathrm{H}$ EVattached to dc-micro grid.

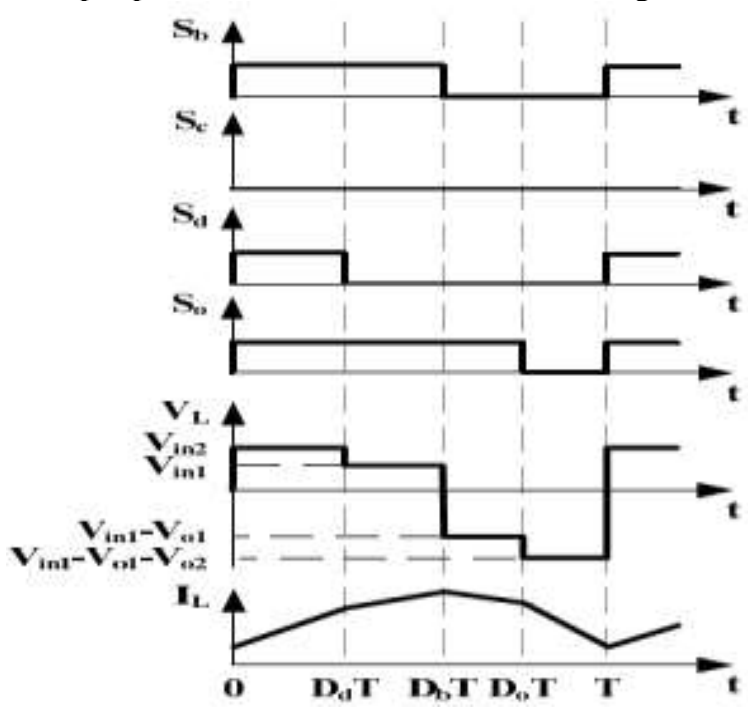

Fig.2. suggested converter in batterydischarging mode. 


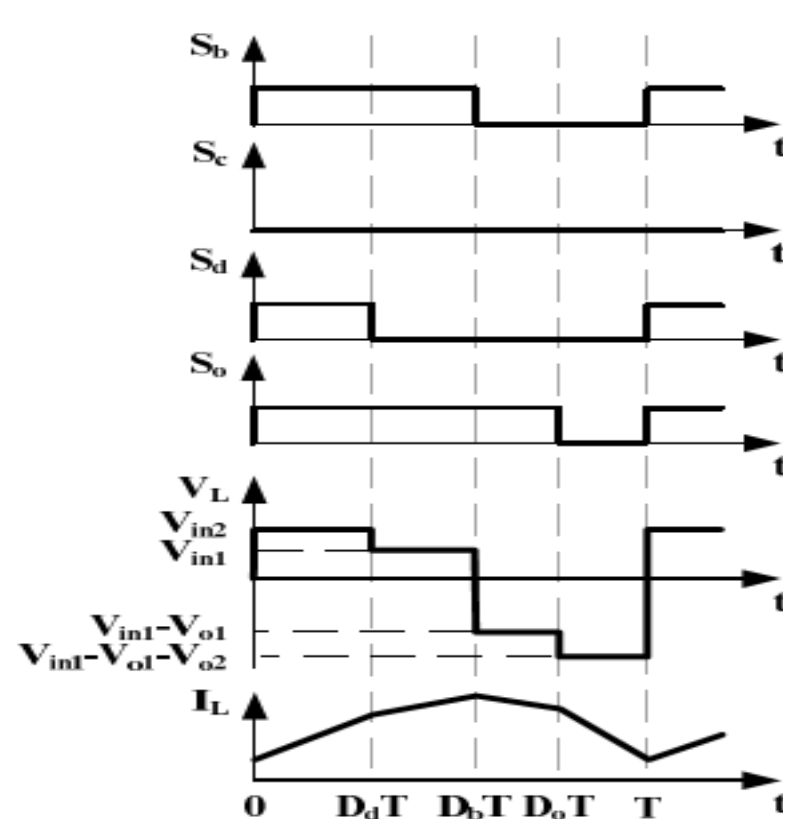

Fig.3. suggested converter in battery charging mode

\section{A. Battery Discharging Mode}

In this operative mode, two input sources $V_{i n 1}$ and $V_{i n 2}$ are providing energy to the loads. This mode, $S c$ is turned OFF, $S_{b}, S_{d}$ and $S_{o}$ are switching. Here, $S_{d}$ can to control battery current to preferred value by adjusting inductor current. Regulation of full output voltage $\left(V_{T}\right)$ to selected value is duty cycle of switch $S b$. Also, voltageoutputVo1 is controlled. By regulation of $V_{T}$ and $V_{o 1}$, output voltages $V_{o 2}, V_{o 3}$ stayregulated too. drive signals of switches, current, voltage waveforms of inductor are presented in Fig.2.

MODE 1: $\left(0<\mathrm{t}<\mathrm{D}_{\mathrm{d}} \mathrm{T}\right)$ : switches $\mathrm{S}_{\mathrm{b}}, \mathrm{S}_{\mathrm{d}}$, and $\mathrm{S}_{\mathrm{o}}$ are switched ON. Because $S_{b}$ is turned ON, diodes $D_{o 1}$, $D_{02}, D_{03}$ are reversely biased, and switch $S c$ is turned OFF. Since $S_{d}$ is turned $O N$ and $V_{\text {in } 1}<V_{\text {in2 }}$, diode Dfc is reversely biased. $\mathrm{Vin}_{2}$ charges inductor $\mathrm{L}$, inductor current rises linearly. Also, capacitors $\mathrm{C}_{1} \sim \mathrm{C}_{3}$ are discharged and deliver energy stored to load resistances $R_{1} \sim R_{3}$.

MODE 2: $\left(D_{d} T<t<D_{b} T\right)$ : switches $S_{b}$ is switched $\mathrm{ON}, \mathrm{S}_{\mathrm{d}}$ is turned OFF, diodes $\mathrm{D}_{\mathrm{o} 1}, \mathrm{D}_{\mathrm{o} 2}, \mathrm{D}_{\mathrm{o} 3}$ are reversely biased., $\mathrm{V}_{\mathrm{in} 1}$ charges inductor $\mathrm{L}$, inductor current rises linearly. In addition, capacitors $C_{1} \sim C_{3}$ are discharged and supply energy stored to load resistances $R_{1} \sim R_{3}$, respectively.

MODE 3: $\left(D_{b} T<t<D_{0} T\right)$ : switches $S_{b}$ and $S_{d}$ are switched OFF. Switch $\mathrm{S}_{\mathrm{o}}$ is turned $\mathrm{ON}$, diodes $\mathrm{D}_{\mathrm{o}}$, $\mathrm{D}_{03}$ are reversely biased. Inductor $\mathrm{L}$ remains discharged and provides energy toC 1 and $\mathrm{R} 1 . \mathrm{C}_{1}$ is charged, $\mathrm{C}_{2}, \mathrm{C}_{3}$ are discharged and supply the energy to load resistances $R_{2} \sim R_{3}$.

MODE 4: $(\mathrm{DoT}<\mathrm{t}<\mathrm{T})$ : All four switches are switched OFF. Diodes $D_{01}$ is reversely biased, $D_{02}$ and $\mathrm{D}_{\mathrm{o} 3}$ remain forward biased. Inductor $\mathrm{L}$ discharged, and energy stored in $L_{1}$ is partly discharged to ideal transformer to supply energy stored to the capacitors $\mathrm{C}_{1} \sim \mathrm{C}_{3}$ and load resistances $\mathrm{R}_{1} \sim \mathrm{R}_{3}$, respectively.

\section{B. Battery Charging Mode}

In this $\mathrm{V}_{\text {in } 1}$ not only deliveries load but also supplies power to $V_{\text {in2. This situation happens when }}$ load power is small and battery needs charging. In this operative mode, switches $\mathrm{S}_{\mathrm{b}}, \mathrm{S}_{\mathrm{c}}$, So, are switching and switch $S_{d}$ is turned OFF. $S_{b}$ is switched to control entire output voltage $\left(\mathrm{V}_{\mathrm{T}}\right)$ to selected value. Regulation of battery charging current to selected value is the duty of switch Sc. Also, voltage output $\mathrm{V}_{\mathrm{o} 1}$ is controlled by switch $\mathrm{S}_{\mathrm{o}}$. By regulation of $\mathrm{V}_{\mathrm{T}}$ and $\mathrm{V}_{\mathrm{ol}}$, the output voltages $V_{0} 2, V_{0} 3$ are regulated too.

MODE1: $\left(0<\mathrm{t}<\mathrm{D}_{\mathrm{b}} \mathrm{T}\right)$ : switch $\mathrm{S}_{\mathrm{d}}$ is switched OFF, $\mathrm{S}_{\mathrm{b}}$, $\mathrm{S}_{\mathrm{c}}, \mathrm{S}_{\mathrm{o}}$ are switched $\mathrm{ON}$, and diodes $\mathrm{D}_{\mathrm{o} 1} \sim \mathrm{D}_{\mathrm{o} 3}$ are reversely biased. $\mathrm{V}_{\text {in } 1}$ charges inductor $\mathrm{L}$, current in inductor rises linearly. Also, capacitors $\mathrm{C}_{1} \sim \mathrm{C}_{3}$ are discharged and transport their energy stored to load resistances $R_{1} \sim R_{3}$, respectively.

MODE 2: $\left(\mathrm{D}_{\mathrm{b}} \mathrm{T}<\mathrm{t}<\mathrm{D}_{\mathrm{c}} \mathrm{T}\right)$ : switches $\mathrm{Sc}$ and So areturned $\mathrm{ON}, \mathrm{S}_{\mathrm{d}}$ and $\mathrm{S}_{\mathrm{b}}$ is switched $\mathrm{OFF}$, diodes $D_{o 1} \sim D_{03}$ arereversely biased. since $V_{\text {in } 1}<V_{\text {in2 }}$, then, in thisperiod of time,current in inductor drops linearly and inductorsupplies the energy to battery. Also, capacitors $\mathrm{C}_{1} \sim \mathrm{C}_{3}$ are discharged and deliverenergy stored to load resistances $R_{1} \sim R_{3}$, respectively.

MODE3: $\left(D_{c} T<t<D_{o} T\right)$ : switches $S_{d}, S_{b}$ and Scare switched OFF. Switch $S_{0}$ is switched ON, diodes $D_{02}$ and $D_{03}$ arereversely biased. inductor is discharged anddelivers the energy to $C_{1}$ and $R_{1}$, current in inductor isreduced linearly. $\mathrm{C}_{1}$ is charged, $\mathrm{C}_{2}, \mathrm{C}_{3}$ aredischarged and supply storedenergy to load resistances $R_{2} \sim R_{3}$.

MODE4: $\quad\left(\mathrm{D}_{\mathrm{o}} \mathrm{T}<\mathrm{t}<\mathrm{T}\right)$ : All four switches are switched OFF. Diodes $D_{01}$ is reversely biased, $D_{02}$ and $\mathrm{D}_{\mathrm{o} 3}$ remain forward biased. Inductor $\mathrm{L}$ discharged, and energy stored in $\mathrm{L}_{1}$ is partially discharged to ideal transformer to supply their energy stored to capacitors $\mathrm{C}_{1} \sim \mathrm{C}_{3}$ and load resistances $R_{1} \sim R_{3}$, respectively.

\section{PV SYSTEM}

A PV scheme directly translates solar energy to electrical energy. The elementary device of PV scheme is PV cell. Cells come together to form arrays. The voltage, current obtainable at terminals of PV scheme directly feed lesser loads for instance lighting systems, DC motors, attach to grid. This PV scheme contains two main parts of PV module are 
balance of system and load. The major balance of system components are charger, battery\& inverter.

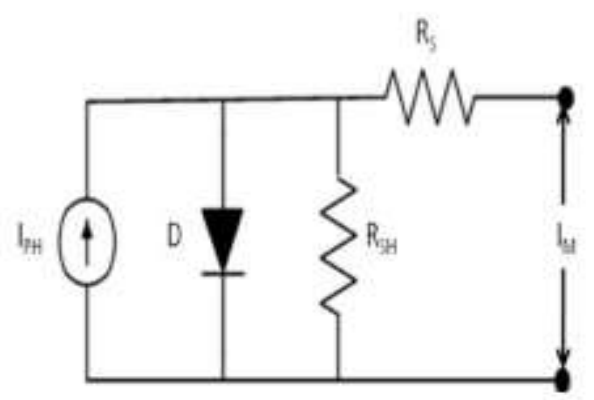

Fig.4. PV device.

A PV cell is a semiconductor diode whose $\mathrm{p}-\mathrm{n}$ junction remains open to light. PV cells are made of semiconductor materials by different developed processes. The equivalent circuit of PV cell is presented in fig.4. PV cell is denoted by current source in parallel by diode. Rs ,Rp denote series, parallel resistance respectively.

\section{SIMULATION RESULTS}

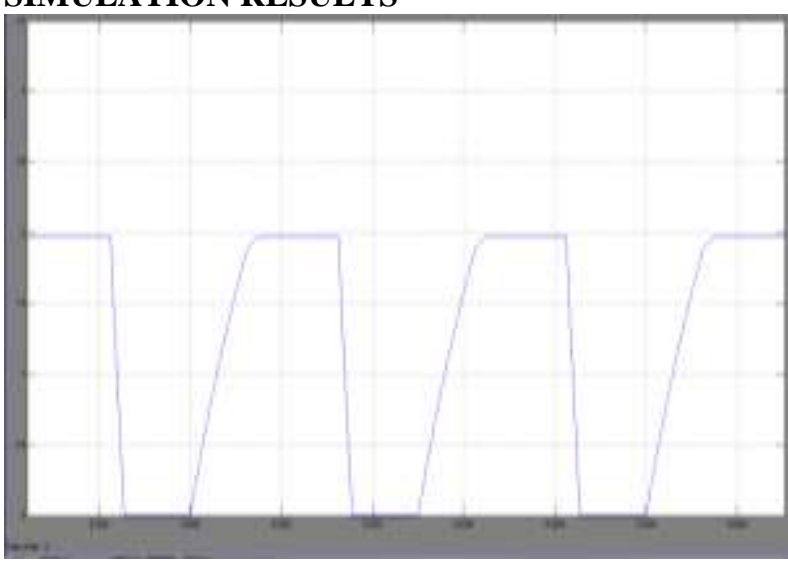

Fig.5 Inductor current in discharging mode

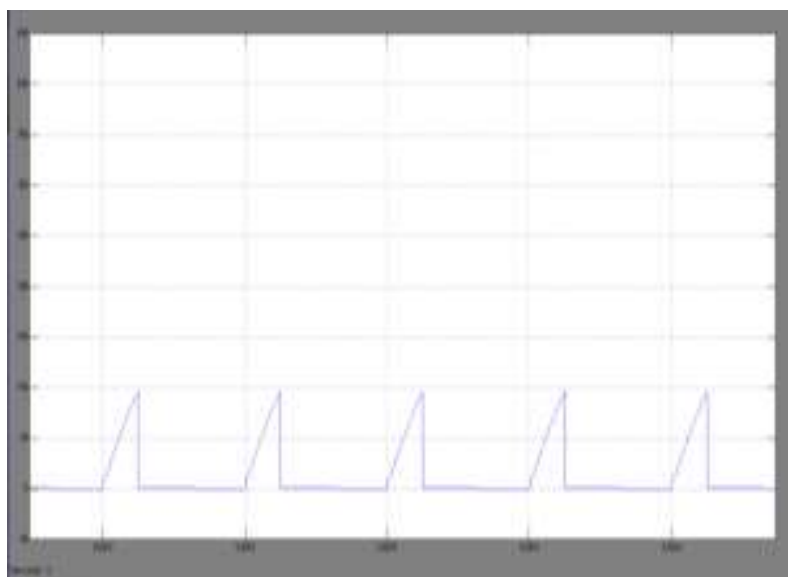

Fig.6 Battery discharging mode Current

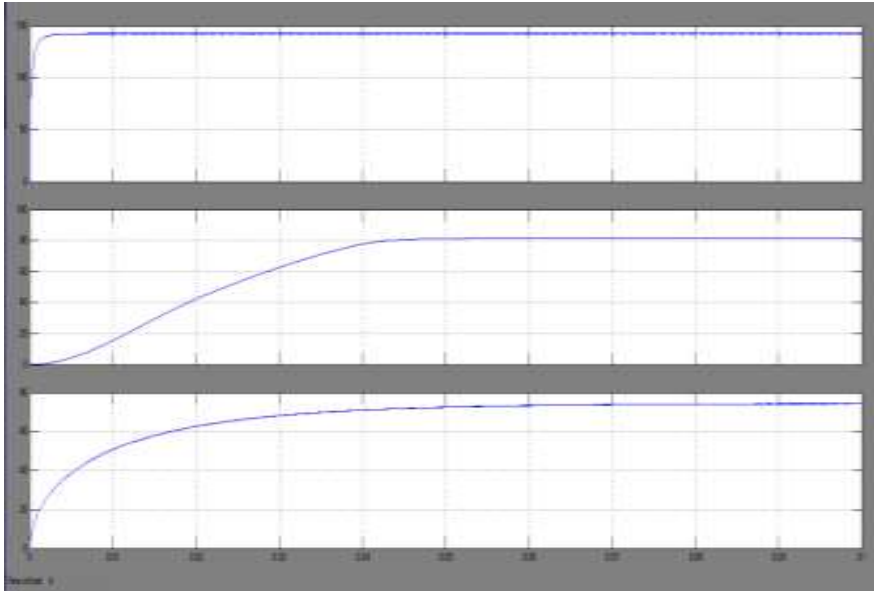

\section{Fig.7 ConverterOutput voltages in discharging} mode

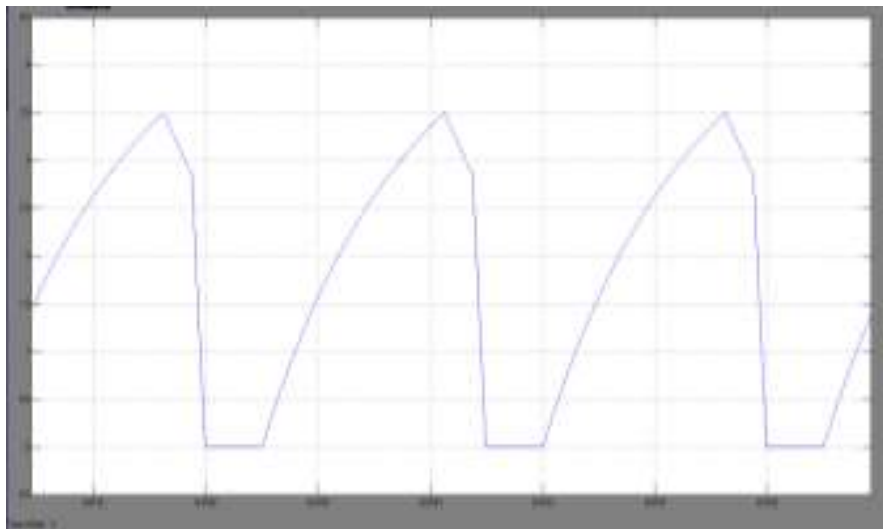

Fig.8Current in Inductorcharging mode

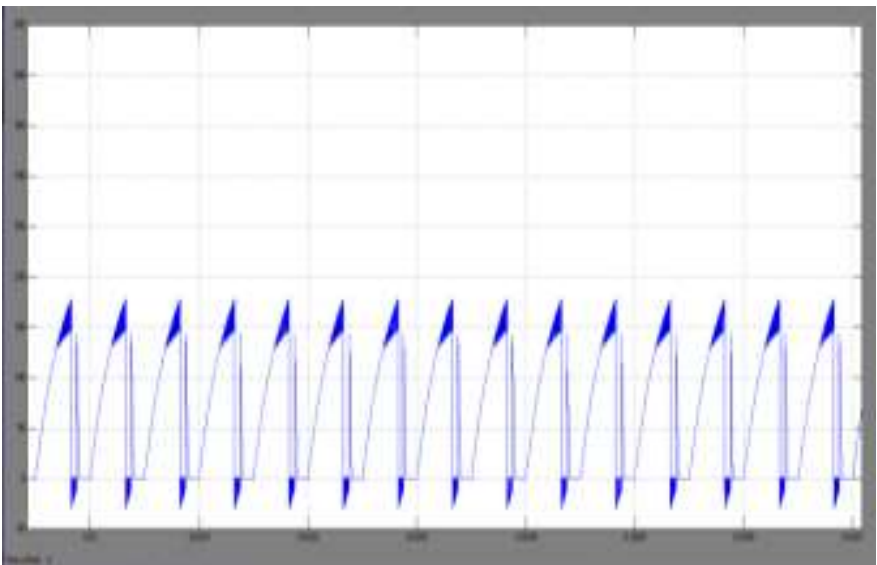

Fig.9 Battery charging mode current 


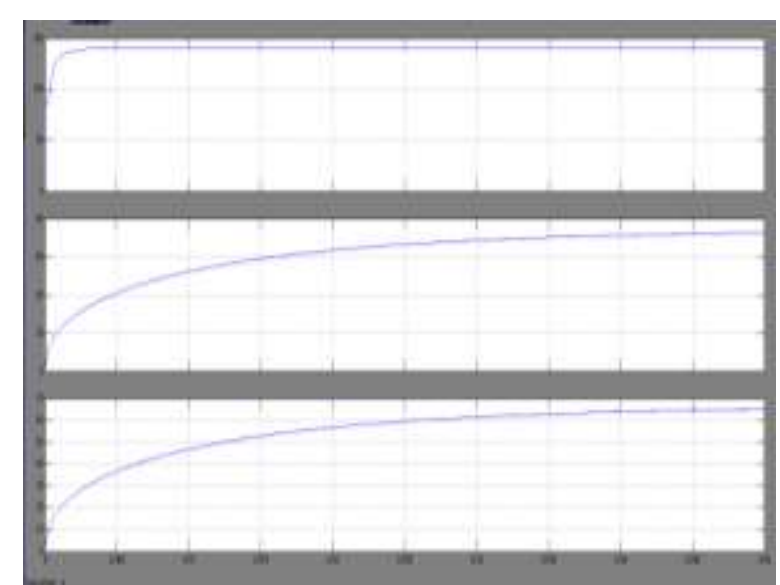

Fig.10 Output voltages of converter in charging mode

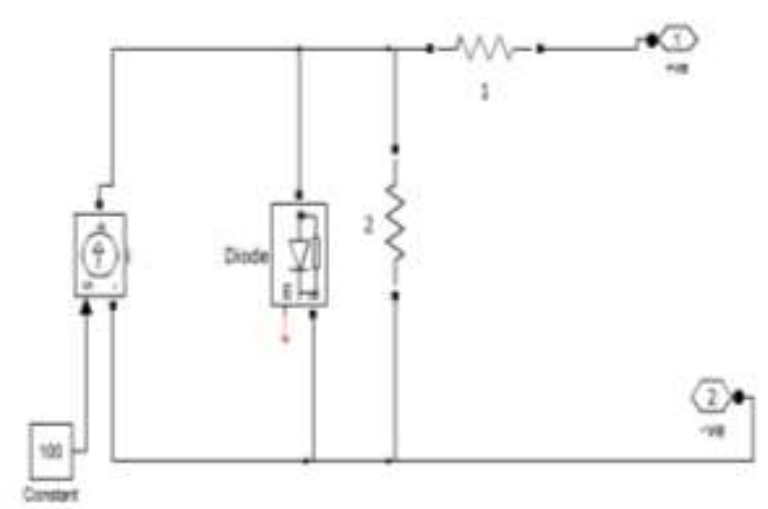

Fig.11 Equivalent circuit of PV

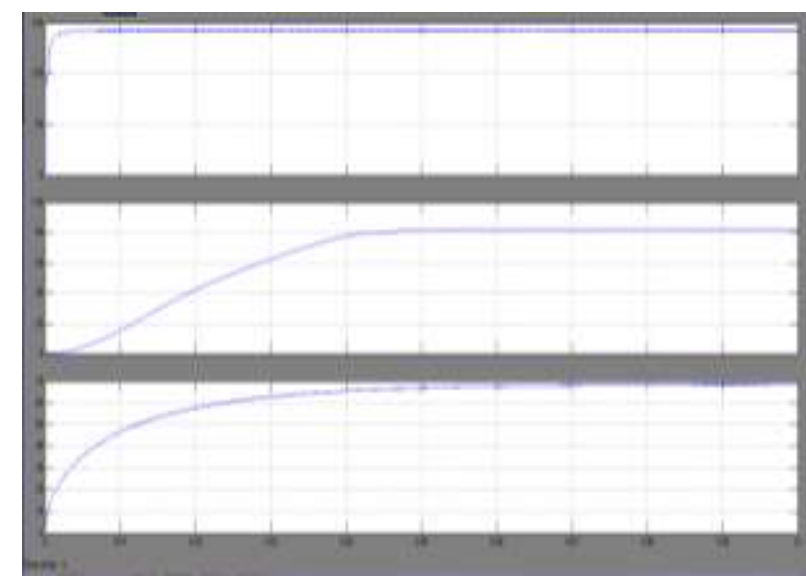

Fig.12converter Output voltages in discharging mode connected with PV system

To validate performance of converter, simulation results have done in battery discharging and charging modes. Inputvoltagesourcesmeasured $\operatorname{are} V_{i n 1}=36 \mathrm{~V}, \quad V_{i n 2}=48 \mathrm{~V}$. output voltage is regulated to $V_{T_{-}}=V_{o 1+} V_{o 2+} V_{o 3}=300 \mathrm{~V}$. Battery current regulated to $I_{b}=1.4 \mathrm{~A}$ and $I_{b}=-0.85 \mathrm{~A}$ for battery dischargingandchargingmodes. Loadresistances are $R_{1}=150 \Omega, R_{2}=75 \Omega$, and $R_{3}=75 \Omega$ for battery discharging and charging modes.
i)Battery Discharging Mode: In this, both input both sources $V_{i n 1}$ and $V_{i n 2}$ are supplying energy to loads. Waveforms of inductor current shown in Fig.5. Also, $S_{c}$ is OFF, $S_{b}, S_{d}$ and $S_{o}$ are controlled. To control output voltage $\mathrm{D}_{\mathrm{b}}, \mathrm{D}_{\mathrm{o}}$ be fixed first, and varying the duty cycle Dd be larger, the output voltage VT is higher, and vice versa. In Fig.6, regulated battery current $\mathrm{Ib}=1.42 \mathrm{~A}$. Also battery current has positive value means the battery has discharged. In Fig.7, the preferred values of output voltages are $\mathrm{Vo} 1=139 \mathrm{~V}, \quad \mathrm{Vo} 2=85.2 \mathrm{~V}$, $\mathrm{Vo} 3=73.1 \mathrm{~V}$, and total output voltage $\mathrm{VT}=297.3 \mathrm{~V}$.

ii)Battery Charging Mode: In this, Vin1 not only supplies load also provides power to Vin2. Waveforms of inductor current are shown in Fig.10. Also Sd is OFF, Sb, Sc, and So are actively controlled. In Fig.11, regulated battery current $\mathrm{Ib}=-0.85 \mathrm{~A}$ obtained. The battery current has negative value means battery has been charged. In Fig.12, the preferred values of output voltages are Vo1 $=143 \mathrm{~V}, \mathrm{Vo}_{2}=79.2 \mathrm{~V}, \mathrm{Vo} 3=71.2 \mathrm{~V}$, and total output $\mathrm{VT}=292.2 \mathrm{~V}$.

\section{Conclusion}

This paper anticipated a three-port converter with high gain, stacked output is simple in structure. The anticipated converter obtains the HEV electrical power from FC, battery sources then changes it to a suitable high voltage, which is applied to dc-micro grid so that dc home usages canusetheelectricitydirectly.Thecircuitoperativepr inciplesanticipated converter in battery discharging, charging modes were presented. The strength of anticipated power converter its performance was verified through simulation results. The charging, discharging battery storage device be controlled efficiently by means of FC source.

\section{References}

1. H. Tao, J. L. Duarte, and M. A. M. Hendrix, "Three-port triple-halfbridge bidirectional converter with zero-voltage switching," IEEE Trans. Power Electronics, vol. 23, no. 2, pp. 782-792, Mar. 2008.

2. P. Thounthong, V. Chunkag, P. Sethakul, B. Davat, and M. Hinaje, "Comparative study of fuel-cell vehicle hybridization with battery or supercapacitor storage device,'IEEE Trans. Vehicular Technology, vol. 58, no. 8, pp. 3892-3905, Oct. 2009.

3. V. A. K. Prabhala, D. Somayajula and M. Ferdowsi, "Power sharing in a double-input buck converter using dead-time control," IEEE Energy Convers. Congr. Expo., 2009. 
4. H. Krishnaswami and N. Mohan, "Threeport series-resonant DC-DC converter to interface renewable energy sources with bidirectional load and energy storage ports," IEEE Trans. PowerElectronics, vol. 24, no. 10, pp. 2289-2297, Oct. 2009.

5. K. Gummi and M. Ferdowsi, "Doubleinput DC-DC power electronic converters for electric-drive vehicles-topology exploration and synthesis using a singlepole triple-throw switch,'IEEE Trans. Industrial Electronics, vol. 57, no. 2, pp. 617-621, Feb. 2010.

6. A. Peyman, S. Pierfederici, F. Meybodytabar, and B. Davat, "An adapted control strategy to minimize dc-bus capacitors of parallel fuel cell/ultracapacitor hybrid system," IEEE Trans. Power Electronics, vol. 26, no. 12, pp. 3843-3852, Dec. 2011.

7. F. Nejabatkhah, S. Danyali, S. H. Hosseini, M. Sabahi, and S. A. Mozaffari Niapour, "Modeling and control of a new three-input DC-DC boost converter for hybrid PV/FC/battery powersystem," IEEE Trans. Power Electronics, vol. 27, no. 5, pp. 23092325, May 2012.

8. Amin, R. T. Bambang, A. S. Rohman, C. J. Dronkers, R. Ortega, and A. Sasongko, "Energy management of fuel cell/battery/supercapacitor hybrid power sources using model predictive control," IEEE Trans. Industrial Informatics, vol. 10, no. 4, pp. 1992-2002, Nov. 2014. 